\title{
Sustained relief of obstructive symptoms for the remaining life of patients following placement of an expandable metal stent for malignant colorectal obstruction
}

\author{
Jorge Manuel Canena ${ }^{1,2,3}$, Manuel Liberato ${ }^{2}$, Inês Marques ${ }^{1}$, Catarina Isabel Rodrigues ${ }^{3}$, Ana Catarina Lagos ${ }^{1}$, \\ Sara Daniela Patrocínio , Miguel J. Tomé ${ }^{4}$, Eduardo Nuno Pires ${ }^{3}$, Carlos Romão ${ }^{1}$, António Pereira Coutinho ${ }^{1,2}$, \\ Pedro Miguel Veiga ${ }^{5}$, Beatriz C. Neves ${ }^{1}$, João Reis Deus ${ }^{2,3}$, Hélder Daniel Além ${ }^{4}$ and José Augusto Gonçalves ${ }^{4}$ \\ ${ }^{1}$ Department of Gastroenterology. Pulido Valente Hospital. Faculty of Medical Sciences. Lisbon, Portugal. ${ }^{2}$ Center of Gas- \\ troenterology. Cuf Infanto Santo Hospital. Lisbon, Portugal. ${ }^{3}$ Department of Gastroenterology. Professor Doutor Fernando \\ Fonseca Hospital. Amadora, Portugal. ${ }^{4}$ Department of Surgery. Centro Hospitalar do Barreiro-Montijo. EPE, Barreiro, \\ Portugal. ${ }^{5}$ Curva de Gauss-Research. Training and Consulting. Canas de Senhorim, Portugal
}

\begin{abstract}
Background: self-expanding metal stents are currently being used as a definitive palliative treatment for malignant colorectal obstruction in patients with incurable disease. Few studies have followed large numbers of patients from stent placement until death, and those few have reported conflicting results in the long-term clinical outcome data.

Aims: this study evaluated the clinical effectiveness of stent placement for malignant colorectal obstruction throughout the patients' lives and related factors affecting stent patency, clinical success and complications.

Methods: this was a multicentre, retrospective study of 89 consecutive patients who had undergone attempted expandable stent placement for symptomatic malignant colorectal obstruction during a 10-year period. Data were collected to analyse the sustained relief of obstructive symptoms throughout the patients' lives, as well as the technical success, immediate clinical success, stent patency, complications, reinterventions, survival, prognostic factors associated with stent patency and long-term clinical efficacy and risk factors for complications.

Results: technical and immediate clinical success were achieved in $95.5 \%$ and $91.0 \%$ of patients, respectively. A total of 68 out of 89 patients (76.4\%) maintained relief of obstruction from stent implantation until death without reintervention. Twenty patients $(22.5 \%)$ had complications including perforation $(n=4 ; 4.5 \%)$, stent obstruction $(n=8 ; 9.0 \%)$, migration $(n=5 ; 5.6 \%)$ and haemorrhage $(n=3 ; 3.4 \%)$. Stent-related mortality was seen in 1 patient $(1.1 \%)$. The estimated median survival and estimated mean stent patency were 87.0 and 322.7 days, respectively. In total, 12 of the initial 89 patients (13.5\%) needed a colostomy for long-term relief of the obstructive symptoms. Univariate and multivariate analysis detected no significant prognostic factors associated with stent patency, long-
\end{abstract}

Received: 28-02-2012

Accepted: 28-08-2012

Correspondence: Jorge Canena. Hospital Cuf Infanto Santo. Travessa do Castro n. ${ }^{\circ}$ 3. 1350-070 Lisbon, Portugal.

e-mail: jmtcanena@live.com.pt term clinical efficacy and risk factors for complications; however, the multivariate logistic model revealed a non-significant trend by which the use of chemotherapy was a risk factor for migration $(\mathrm{OR}=11.89 ; p=0.06)$.

Conclusions: for palliation of incurable malignant colorectal obstruction, expandable stents can provide sustained relief of obstruction in approximately $75 \%$ of patients. The procedure is associated with acceptable morbidity, need for reintervention and minimal mortality.

Key words: Self-expanding metal stent. Colorectal obstruction. Endoscopic definitive palliation.

Canena JM, Liberato M, Marques I, Rodrigues CI, Lagos AC, Patrocínio SD, Tomé MJ, Pires EN, Romão C, Coutinho AP, Veiga PM, Neves BC, Deus JR, Além HD, Gonçalves JA. Sustained relief of obstructive symptoms for the remaining life of patients following placement of an expandable metal stent for malignant colorectal obstruction. Rev Esp Enferm Dig 2012;104:418-425.

\section{INTRODUCTION}

Colorectal cancer is one of the most common malignancies worldwide (1). In patients with colorectal cancer, obstruction occurs in 15 to $20 \%$ (2). Most of these patients have advanced disease and are often elderly, with significant comorbidities (2-4). In this group of patients, curative resection is not frequently feasible $(4,5)$. Therefore, palliation is the primary aim in these patients $(3,6,7)$. Emergency surgical decompression is associated with high mortality and morbidity figures $(8,9)$. In addition, surgery often involves creation of a colostomy, reversal of which would not be possible in up to $50 \%$ of patients. This inter- 
vention would thus have a profound negative impact on quality of life (7-9).

First reported by Dohmoto et al. (10), self-expandable metal stents (SEMS) have been increasingly used as a minimally invasive, nonsurgical treatment for either palliation or pre-operative bridging to 1-stage surgery procedure in malignant colorectal obstruction (1-10). A pooled analysis of 1,198 patients demonstrated an immediate clinical success rate of $92.7 \%$ in the palliative group (11); however, complications were recorded including perforations (3.8\%), migration (11.8\%), re-obstruction (7.3\%) and stent-related mortality $(0.58 \%)$. A systematic review comparing endoscopic palliation with surgery suggested that stenting was associated with more positive outcomes when compared with surgery, including overall shorter hospital stays, and a lower rate of serious adverse events (9).

Although the initial decompression rate using SEMS in acute colorectal obstruction is high, there are concerns about the long-term clinical efficacy and late complications of the stents in the palliative setting. Few studies followed the majority of patients until death after stent placement, and there is a small amount of long-term clinical outcomes data with conflicting results. Recent studies reported that a single palliative SEMS implantation is associated with long-term (until death) success rates up to $80 \%$, although the complication rate is nearly $25 \%(6,7,12,13)$. These results, however, conflict with other studies reporting short- and longterm clinical failure in more than 50\% of patients, along with a high number of severe complications $(4,5)$. Furthermore, several risk factors have been associated with stent patency, complications and clinical outcomes, as well as with conflicting results $(1,6,12-14)$. The question remains: are SEMS used for definitive palliation of malignant colorectal obstruction as successful as those used as a bridge to surgery?

The aim of this study was to evaluate the sustained relief of obstructing symptoms from stent placement until death in all patients, including the incidence of complications and the need for reinterventions, risk factors for complications and prognostic factors associated with stent patency and long-term clinical efficacy after SEMS placement in the palliative treatment of patients with malignant colorectal obstruction.

\section{METHODS}

\section{Patients and setting}

Interventional endoscopy database records from 4 institutions were retrospectively reviewed to identify all patients who had undergone consecutive attempted SEMS placement for symptomatic malignant colorectal obstruction between October 2001 and August 2011. The following criteria were used for inclusion in this study: 1-palliative intent to treat in patients with obstructive symptoms, 2-histologically confirmed malignancy, 3-inoperable disease based on advanced tumour stage, metastatic disease or medical comorbidity and 4-complete follow-up until patient death at the time of data collection. The exclusion criteria were as follows: a) evidence of bowel perforation or other obstructions in the gastro-intestinal tract; b) previous palliative stent placement for the same condition; and c) patients with tumoral strictures and no obstructive symptoms.

Colorectal obstruction was diagnosed by clinical findings and confirmed using a colonoscopy or computed tomography. The data were collected from a variety of sources, including patients' charts (manual and electronic), clinical notes, radiology and endoscopic reports, our prospective database, follow-up clinic visits and telephone interviews with treating physicians or family during follow-up or at the time of manuscript preparation. Several investigators participate in this task to obtain the following data: patient demographics, technical success, clinical success, stent model, stent diameter, type of malignancy (intrinsic or extrinsic), location of obstruction, complications, reinterventions, palliative chemotherapy, need for surgery and survival. Patients with incomplete data were excluded from the study. This study was conducted at 4 institutions ( 3 tertiary referral academic centres and 1 general district hospital). All patients provided informed written consent prior to their procedures. Each ethics committee involved approved this retrospective study.

\section{Technique and stents}

The technique used for stent placement has been described elsewhere $(2,15)$. Briefly, all procedures were performed with patients in the left lateral position under sedation with propofol administered by an anaesthesiologist. In some cases, patients were shifted to the supine position during the procedure and stent deployment for a better anatomic view under fluoroscopy. No oral bowel preparation was given, and patients underwent bowel cleansing by using repeated enemas. The stricture was assessed with a triple-lumen biliary catheter and a biliary guidewire under endoscopic and fluoroscopic guidance. The length of the stricture was assessed either endoscopically or fluoroscopically by injection of water-soluble contrast. Balloon dilatation of the stricture was not performed in all cases. The distal end of the stenosis was marked with a haemostatic clip. The stent delivery system was advanced through the stricture, and the stent was deployed under fluoroscopic and endoscopic control. Stent placement was performed by one of several endoscopists (7 in total), during regular time, all with experience in pancreatobiliary endoscopy. Each endoscopist had, at least, a mean number of attempts per month of 1.5. Three different types of stent were used: a) from October 2001 to November 2005, the Wallstent enteral stent (Boston Scientific, Natick, Massachusetts, USA), 20 or $22 \mathrm{~mm}$ in diameter and 6 or $9 \mathrm{~cm}$ in length was used by a through- 
the-scope method; b) between October 2002 and November 2005, the Ultraflex Precision (Boston Scientific, Natick, Massachusetts, USA), $25 \mathrm{~mm}$ in diameter (mid-body) and 6,9 or $12 \mathrm{~cm}$ in length was used for several cases of malignant obstruction located in the rectum or distal sigmoid colon; and c) from November 2005 to the end of this study, the WallFlex colonic stent (Boston Scientific, Natick, Massachusetts, USA), 22 or $25 \mathrm{~mm}$ in diameter (mid-body) and 6,9 or $12 \mathrm{~cm}$ in length was used in all cases. The stent diameter and length were selected at the discretion of the endoscopist.

Twenty-four hours after stent deployment, all patients underwent a plain abdominal X-ray to verify stent expansion and correct position and to assess relief of obstruction. After stent insertion, all patients were placed on a lowresidue diet with laxatives to prevent stool impaction of the stent.

\section{End points and definitions}

The primary endpoint was long-term clinical efficacy, defined as sustained relief of obstructive symptoms without reintervention. Secondary endpoints included technical success, immediate clinical success, stent patency, complications, reinterventions, survival, prognostic factors associated with stent patency and long-term clinical efficacy and risk factors for complications. Technical success was defined as accurate stent deployment across the stricture, with patency visualised both fluoroscopically and endoscopically. Immediate clinical success was defined as colonic decompression and relief of obstructive symptoms within 24 hours after stent placement $(1,6)$. Stent patency was defined as the period between stent placement and recurrence of obstructive symptoms caused by stent dysfunction due to malignant stent obstruction (tumour overgrowth or ingrowth) or migration. Complications were defined as any adverse event related to stent placement. Complications were also divided into early (within 7 days) and late. Stent migration was diagnosed if the stent moved from its initial position and was unable to cover the entire stenosis, leading to recurrence of obstructive symptoms. Reintervention was defined as any procedure performed after the initial stent placement, including endoscopic resolution of stool impaction, subsequent colonic stent insertion due to malignant stent restenosis or migration, balloon dilatation, stent removal, argon plasma coagulation or surgery.

\section{Follow-up}

Follow-up data were obtained by reviewing patients' electronic and manual charts and clinical notes from regular clinic visits and by performing telephone interviews with the treating physician or family at the time of manuscript preparation. Patients were followed until death in all cases. In the case of recurrent obstructive symptoms during fol- low-up, patients contacted their treating physician in the institution for clinical evaluation. During clinical evaluation, repeated colonoscopy was conducted for suspected stent dysfunction. Reinterventions were performed when necessary, considering the clinical situation and patient preference. Elective colostomy was performed after failure of endoscopic therapy.

\section{Statistical analysis}

All study outcomes were evaluated on an intention-totreat basis. The cumulative time until complications, stent patency and patient survival were estimated by the KaplanMeier product limit method. For the calculation of the stent patency period, death before stent dysfunction was considered a censored observation. The 95\% CI for long-term clinical efficacy was calculated with the Clopper-Pearson (exact) method. Potential risk factors for complications and prognostic factors associated with long-term clinical efficacy were assessed by univariate analysis followed by a multiple logistic regression. Univariate analysis was conducted using the qui-square test for categorical variables and Student's $t$ test for continuous variables. To determine independent prognostic factors potentially associated with stent patency, multivariate Cox proportional hazard models were used. Age, sex, stent diameter (22 $\mathrm{mm}$ or less or $25 \mathrm{~mm}$ ), type of malignancy (intrinsic or extrinsic), location of obstruction (left colon, right colon, anastomosis) and palliative chemotherapy were the variables included in the univariate and multivariate analysis. All reported $p$ values were for a 2 -tailed test, and a $p<0.05$ was considered statistically significant. All statistical analyses were performed using the software package SPSS (Statistical Package for the Social Sciences) 18 (IBM Corporation, New York, USA).

\section{RESULTS}

In total, 89 patients (54 males and 35 females) with a mean age of 74.0 years (range: $39-97$ years) were enrolled in the study. The patients' baseline data are shown in Table I.

\section{Technical and immediate clinical success}

Placement of a colorectal SEMS was attempted in 89 patients. Successful insertion was achieved in 85 of 89 patients (95.5\%). There were no differences in technical success rates for stents placed in the right side of colon compared with the left side of the colon (93.8vs. 95.9\%; $p=0.71$ by univariate analysis). In 4 patients, technical failure during stent placement was caused by the inability to pass the stricture with a guidewire. All 4 patients underwent successful emergent surgery with a colostomy. Immediate clinical success was achieved in 81 of 89 attempts $(91.0 \%)$ and in 81 of 85 successfully inserted stents (95.3\%). Of the 85 patients 
Table I. Baseline patient data

\begin{tabular}{|c|c|}
\hline \multicolumn{2}{|l|}{ Characteristic } \\
\hline \multicolumn{2}{|l|}{ Gender } \\
\hline Male, n (\%) & $54(60.7)$ \\
\hline Female, n (\%) & $35(39.3)$ \\
\hline Age (years), mean \pm SD (range) & $74.0 \pm 10.6(39-97)$ \\
\hline \multicolumn{2}{|l|}{ Site of obstruction } \\
\hline Rectum, n (\%) & $18(20.2)$ \\
\hline Sigmoid colon, n (\%) & $49(55.1)$ \\
\hline Descending colon, n (\%) & $4(4.5)$ \\
\hline Splenic flexure, n (\%) & $2(2.2)$ \\
\hline Transverse colon, n (\%) & $12(13.5)$ \\
\hline Hepatic flexure, n (\%) & $4(4.5)$ \\
\hline \multicolumn{2}{|l|}{ Stricture location } \\
\hline Right side of the colon, $\mathrm{n}(\%)$ & $16(18.0)$ \\
\hline Left side of the colon, n (\%) & $73(82.0)$ \\
\hline \multicolumn{2}{|l|}{ Aetiology } \\
\hline Colorectal, n (\%) & $85(95.5)$ \\
\hline Extrinsic compression, n (\%) & $4(5.1)$ \\
\hline \multicolumn{2}{|l|}{ Type of stent } \\
\hline Wallstent, n (\%) & $39(43.8)$ \\
\hline Ultraflex, n (\%) & $10(11.2)$ \\
\hline WallFlex, n (\%) & $40(44.9)$ \\
\hline \multicolumn{2}{|l|}{ Stent diameter, mm } \\
\hline$" 22, \mathrm{n}(\%)$ & $39(43.8)$ \\
\hline$\geq 25, \mathrm{n}(\%)$ & $50(56.2)$ \\
\hline \multicolumn{2}{|l|}{ Chemotherapy } \\
\hline Yes, n (\%) & $24(27.0)$ \\
\hline No, n (\%) & $65(73.0)$ \\
\hline
\end{tabular}

SD: standard deviation.

with technical success, only in 81 patients improved their obstructive symptomatology because the remaining 4 patients developed stent-related perforations, as discussed later. One patient with advanced disease died several hours after the onset of the complication. The other 3 patients underwent successful emergency surgery and required no further intervention until death.

\section{Sustained relief of obstruction}

Relief of obstruction without intervention was maintained from stent insertion until death in 68 of 89 patients (76.4\%, 95\% CI 66.2-84.8\%) (Fig. 1 and Table II) and in 68 of the 81 patients $(83.9 \%)$ in whom insertion had immediate clinical success. The long-term clinical efficacy rates by location were as follows: 14 of 16 patients (87.5\%) with stents placed in the right side of the colon and 54 of 73

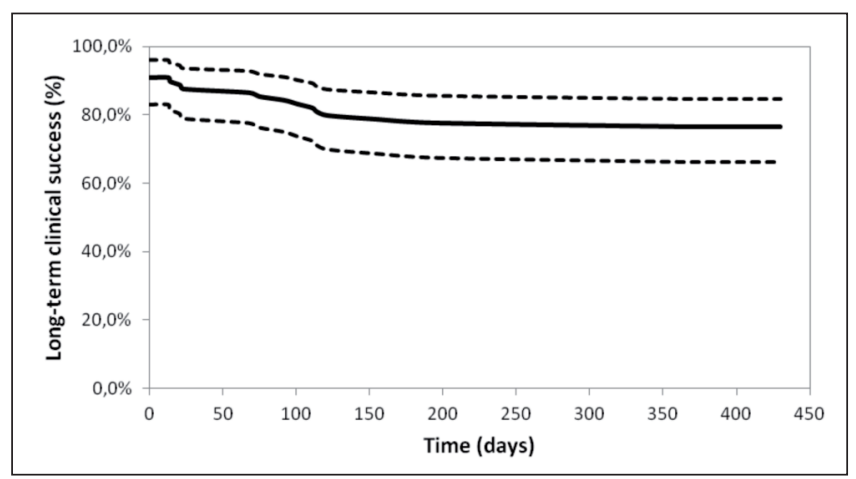

Fig. 1. Long-term sustained relief of obstruction without reintervention throughout the patients' lives after palliative stent placement (solid line) and $95 \% \mathrm{Cl}$ (dashed line).

Table II. Outcomes after attempted stent placement for symptomatic malignant colorectal obstruction in 89 patients

\section{Outcomes}

Technical success, n/total (\%)

Immediate clinical success, n/total (\%)

$84 / 89(95.5)$

Long-term sustained relief of obstruction

without intervention, n/total (\%)

$81 / 89(91.0)$

Long-term sustained relief of obstruction

after subsequent stent placement because

of stent dysfunction, n/total (\%)

$68 / 89(76.4)$

Patients needing a colostomy for long-term

relief of the obstructive symptoms, n/total (\%) 12/89 (13.5)

Complications, n/total (\%)

$20 / 89(22.5)$

Mortality procedure related, n/total (\%)

patients $(74.0 \%)$ with stents placed in the left side of the colon $(p=0.25)$. During follow-up 6/89 patients $(6.7 \%)$ were readmitted for suspected reobstruction that was proven to be attributed to disease progression and not to SEMS dysfunction as these patients were submitted to colonoscopy. Univariate (Table III) and multivariate analysis (logistic model) showed that age, sex, stent diameter, type of malignancy, location of the stricture and palliative chemotherapy were not significantly associated with longterm clinical efficacy.

\section{Complications, reinterventions and risk factors for complications}

In total, 20 of 89 patients $(22.5 \%)$ experienced complications after the procedure (Table IV). Early complications, namely perforations, were seen in 4 of 89 patients $(5.1 \%)$. Perforations occurred after stent placement after a mean interval of 1 day (range, 1-2). One patient died as a conse- 
Table III. Univariate analysis of prognostic factors associated with long-term clinical efficacy

\begin{tabular}{|c|c|c|c|}
\hline & Clinical & Success, $n(\%)$ & \\
\hline & Yes & No & $p$ \\
\hline Sex & & & 0.71 \\
\hline Male & $42(77.8)$ & $12(22.2)$ & \\
\hline Female & $26(74.3)$ & $9(25.7)$ & \\
\hline Age (Mean \pm SD) & $73.8 \pm 10.90$ & $74.9 \pm 9.8$ & 0.67 \\
\hline Stricture location & & & 0.25 \\
\hline Right colon & $14(87.5)$ & $2(12.5)$ & \\
\hline Left colon & $54(74.0)$ & $19(26.0)$ & \\
\hline Stent diameter & & & 0.16 \\
\hline $22 \mathrm{~mm}$ & $27(69.2)$ & $12(30.8)$ & \\
\hline 25 mm & $41(82.0)$ & $9(17.0)$ & \\
\hline Aetiology & & & 0.20 \\
\hline Colorectal & $66(77.6)$ & $19(22.4)$ & \\
\hline Extrinsic & $2(50.0)$ & $2(50.0)$ & \\
\hline Chemotherapy & & & 0.45 \\
\hline Yes & $17(70.8)$ & $7(29.2)$ & \\
\hline No & $51(78.5)$ & $14(21.5)$ & \\
\hline
\end{tabular}

SD: standard deviation.

quence of the perforation (stent-related mortality: 1.1\%), and the remaining 3 patients underwent successful emergent surgery. Following surgery, these patients were free from obstruction until death. Late complications were observed in 16 of 89 patients $(17.9 \%)$, including stent obstruction $(\mathrm{n}=8 ; 9.0 \%)$, migration $(\mathrm{n}=5 ; 5.6 \%)$ and haemorrhage $(\mathrm{n}=3 ; 3.4 \%)$. Malignant restenosis was experienced at 58, $68,75,92,101,111,121$ and 366 days after stent placement (median time to reobstruction: 96.5 days). One patient with reobstruction required successful surgery with a colostomy, and in the remaining 7 patients, stent obstruction was successfully managed by subsequent stent insertion with resolution of obstructive symptoms. All of these 7 patients maintained relief of obstructive symptoms until death. Bleeding from the tumour through the mesh of the stent was seen in 3 patients. The haemorrhage was successfully managed by endoscopic intervention using argon plasma coagulation without the need for transfusion. Migration was encountered in 5 patients at 14, 21, 23, 114 and 196 days after stent placement (median time to migration: 23 days). One patient with migration was successfully managed by subsequent insertion of a stent with a larger diameter, and the remaining 4 patients were submitted to surgery with colostomy. All 5 patients were free from obstructive symptoms until death. Kaplan-Meier analysis estimated that the mean time to complications after stent insertion was 288.2 days (range, 1-366) (95\% CI 237.4-237.4) (Fig. 2). In total, 12 of the initial 89 patients (13.5\%) needed
Table IV. Complications and management

\begin{tabular}{lcc}
\hline Complications & $n(\%)$ & Management ( $n)$ \\
\hline $\begin{array}{l}\text { Perforation } \\
\text { Stent dysfunction } \\
\text { Obstruction }\end{array}$ & $\begin{array}{c}13(4.5) \\
8(9.0)\end{array}$ & $\begin{array}{c}\text { Surgery (4) } \\
\text { Stent insertion (7) }\end{array}$ \\
Migration & $5(5.6)$ & $\begin{array}{c}\text { Surgery (4), subsequent } \\
\text { stent insertion (1) }\end{array}$ \\
Haemorrhage & $3(3.4)$ & Argon plasma coagulation (3) \\
Total & $20(22.5)$ & - \\
\hline
\end{tabular}

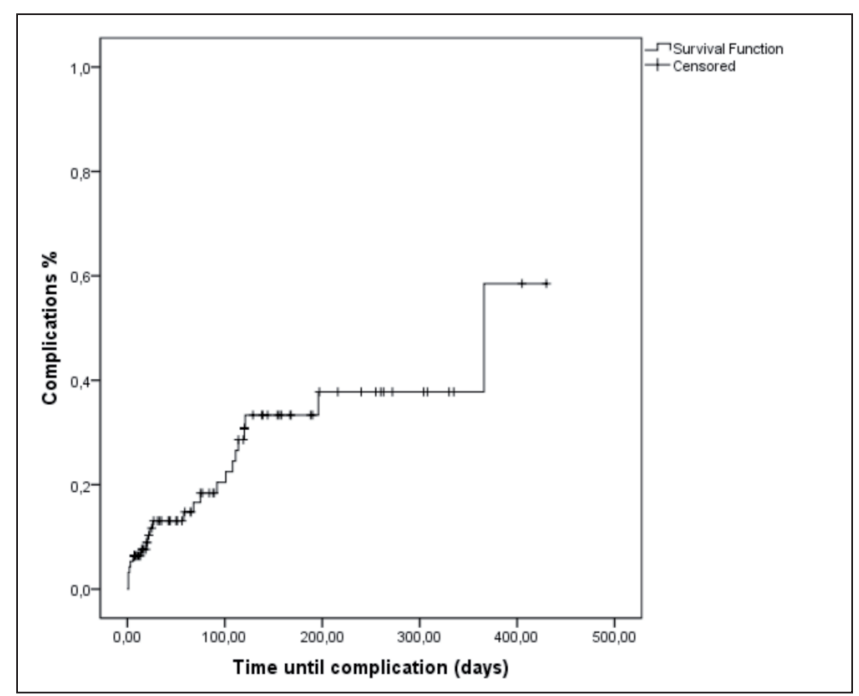

Fig. 2. Kaplan-Meier estimated time until the onset of complications.

a colostomy for long-term relief of the obstructive symptoms. Univariate analysis and the multivariate logistic model revealed no significant risk factors associated with complications; however, a logistic model for individual complications (migration, obstruction and perforation) showed a non-significant trend towards the use of palliative chemotherapy as a risk factor for migration $(\mathrm{OR}=11.89$; 95\% CI=0.90-157.47; $p=0.06)($ Table V).

\section{Survival, stent patency and prognostic factors for stent patency}

The median and mean survival periods were 87.0 (range, 4-565) (95\% CI 43.9-130.1) and 116.0 days (95\% CI 92.5139.5) (Fig. 3), respectively. The survival rates were $21.3 \%$ (95\% CI $12.8-29.9 \%)$ at 6 months and $4.5 \%$ (95\% CI 0.2$8.8 \%$ ) at 1 year. Loss of stent patency occurred in 13 of 89 patients $(14.6 \%)$ as a result of stent dysfunction (stent obstruction in 8 patients and migration in 5 patients). The mean stent patency was 322.7 days (range, 14-366) (95\% CI 
Table V. Results of a multivariate logistic model to evaluate risk factors for complications

\begin{tabular}{|c|c|c|c|c|c|c|c|c|c|}
\hline & \multicolumn{3}{|c|}{ Migration } & \multicolumn{3}{|c|}{ Obstruction } & \multicolumn{3}{|c|}{ Perforation } \\
\hline & OR & $95 \% \mathrm{Cl}$ & $p$ & OR & $95 \% \mathrm{Cl}$ & $p$ & OR & $95 \% \mathrm{Cl}$ & $p$ \\
\hline Age & 1.05 & $0.92-1.19$ & 0.47 & 1.12 & $0.99-1.26$ & 0.08 & 0.97 & $0.87-1.08$ & 0.55 \\
\hline Sex-female & 3.14 & $0.30-32.54$ & 0.34 & 3.02 & $0.51-17.91$ & 0.22 & 0.43 & $0.04-4.56$ & 0.48 \\
\hline $\begin{array}{l}\text { Stent diameter } \\
(22 \mathrm{~mm})\end{array}$ & 1.19 & $0.14-10.45$ & 0.89 & 2.06 & $0.35-12.11$ & 0.42 & 0.49 & $0.05-5.13$ & 0.55 \\
\hline Location & & & & & & & & & \\
\hline Right colon & 0.00 & NC & 0.99 & 0.41 & $0.04-4.56$ & 0.47 & 0.00 & NC & 0.99 \\
\hline Aetiology & & & & & & & & & \\
\hline Colorectal & 0.25 & $0.01-4.53$ & 0.35 & 0.35 & $0.02-5.13$ & 0.45 & 0.00 & NC & 0.99 \\
\hline CT & 11.89 & $0.90-156.47$ & 0.06 & 2.48 & $0.50-13.08$ & 0.35 & 0.00 & NC & 0.99 \\
\hline
\end{tabular}

CT: Chemotherapy; NC: not computed.

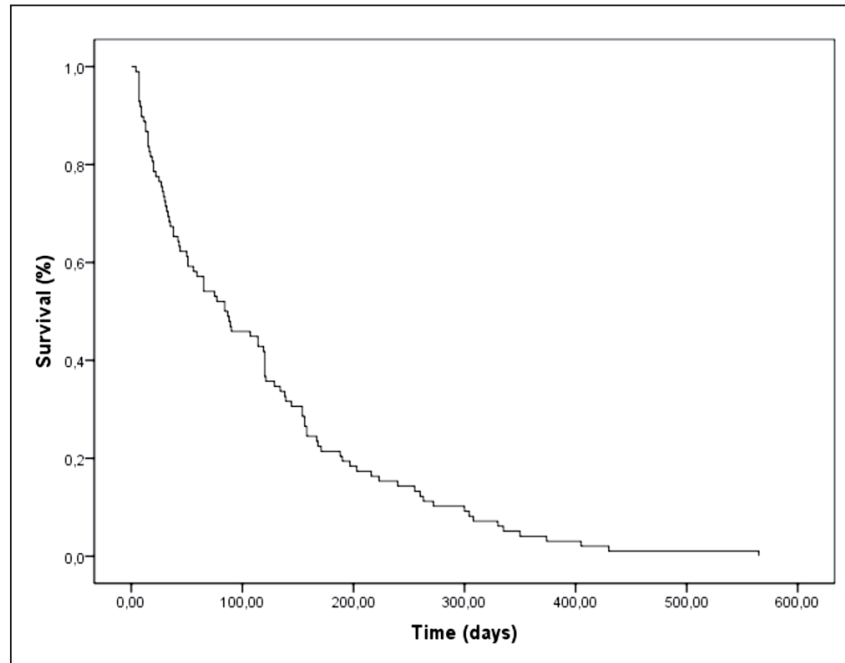

Fig. 3. Kaplan-Meier curves of estimated survival.

273.4-372.0) (Fig. 4). Kaplan-Meier method did not estimate median stent patency because more than $50 \%$ of observations were censored early in the analysis. Multivariate Cox regression analysis showed that age (HR 1.07, 95\% CI 0.97-1.18; $p=0.15$ ), sex-female (HR 3.95, 95\% CI 0.80-19.56, $p=$ 0.92 ), stent diameter-22mm (HR 1.14, 95\% CI 0.30-4.25; $p=0.85$ ), type of malignancy-colorectal (HR $0.22,95 \% \mathrm{CI}$ 00.4-1.27, $p=0.09$ ), location of the stricture-right/left (HR $0.15,95 \%$ CI $0.01-1.54 ; p=0.11$ ), and palliative chemotherapy (HR 5.51, 95\% CI 0.86-35.29; $p=0.07$ ) were not significantly associated with stent patency.

\section{DISCUSSION}

According to our findings in a retrospective, single-arm, multicentre study, the use of a SEMS for definitive palliation of malignant colorectal obstruction was associated with

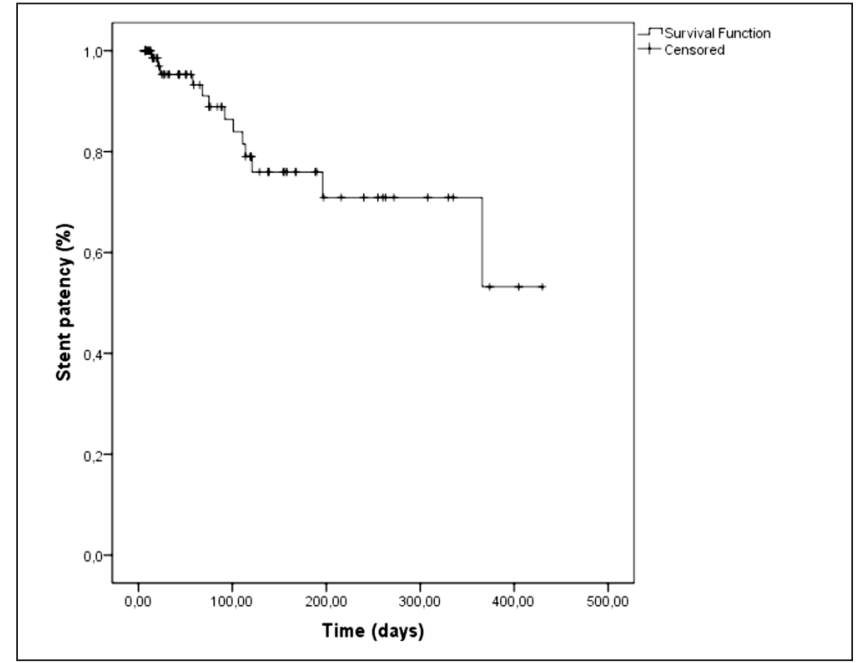

Fig. 4. Estimated stent patency based on Kaplan-Meier analysis.

the sustained, lifelong relief of obstructive symptoms without the need for reintervention in $76.4 \%$ of patients. The complication rate was $22.5 \%$, and perforation was seen in $4.5 \%$ of the patients. The stent-related mortality rate was $1.1 \%$. In total, 12 of the initial 89 patients $(13.5 \%)$ needed a colostomy for long-term relief of the obstructive symptoms. The multivariate logistic model revealed a non-significant trend by which the use of palliative chemotherapy was a risk factor for migration $(p=0.06)$.

SEMS were developed to provide rapid and effective relief of colonic obstruction and are an effective alternative to surgery. Several studies have suggested that there are advantages of stents over emergency surgery, either as a bridge to elective 1-stage surgery or as a palliative treatment $(1,9,16)$. Three randomised trials have compared colostomy to endoscopic stenting for palliation of malignant colorectal obstruction $(5,17,18)$. One study enrolling 30 patients showed that placement of a metal stent yielded similar out- 
comes when compared with surgery, but the stent was associated with a better quality of life for the patient and with fewer costs (17). In another study enrolling 22 patients, endoscopic stenting was significantly more effective in terms of operative time, restoration of bowel function, restoration of oral food intake and reduction in median hospitalisation (18). However, a recent trial was terminated prematurely because of the high number of perforations (n $=6$ ) in the nonsurgical arm, which resulted in 3 deaths among 10 patients (5). The authors concluded that the high perforation rate could be either specifically WallFlex-related or enteral-stent-related in patients on chemotherapy. In contrast, one study conducted in the same year as the previously cited randomised trial and using the WallFlex stent was associated with a perforation rate below 5\% (19), which is in line with previous studies using other stents $(11,14,20)$.

The results of prospective trials and of recent retrospective studies further demonstrated the effectiveness of SEMS in the palliative management of malignant colorectal obstruction $(6,7,12-14,21)$. In this study, sustained relief of obstructive symptoms without reintervention was the primary outcome. A total of $76.4 \%$ of the patients were free from obstruction until death. These results were measured on an intention-to-treat basis; per-protocol analysis yielded an improved long-term clinical efficacy of $83.9 \%$. Furthermore, among the $14.6 \%$ of patients in whom reobstruction was caused by stent dysfunction, the placement of another stent prolonged the benefit of the majority $(8 / 13,61.5 \%)$ of endoscopically treated patients. In this study, no significant prognostic factors for long-term clinical efficacy have emerged. One study reported that shorter stents $(<10 \mathrm{~cm})$ and distal colorectal obstruction are associated with better stent outcomes (12). One additional important observation in our study is the similar long-term clinical efficacy between stents placed in the left side of the colon and SEMS placed in the right side of the colon $(87.5 \mathrm{vs}$. $74.0 \%$ respectively). In this study, the number of included patients with obstruction in the proximal colon was relatively high $(\mathrm{n}=$ 16), and the effectiveness of proximal colon stenting was previously reported in a multicentre retrospective study of 21 patients (22). Finally, in the present study, there was a substantial difference between the estimated mean survival (116.0 days) and mean stent patency (322.7 days), suggesting that colorectal stenting is able to keep the majority of patients free from obstruction until death.

Few studies have addressed the long-term sustained relief of colorectal obstruction from stent placement until death, as the majority of reports have either limited follow-up or a significant number of patients lost to follow-up. A prospective multicentre study addressed the long-term clinical efficacy of colorectal stents in 44 patients with malignant colonic obstruction. During the study, 14 patients died and $12 / 14(86 \%)$ of the non-survivors were clinical successes (7). A large retrospective study conducted over a 9year period analysed the outcomes of 168 patients who underwent SEMS placement for palliation. At 6 months, the estimated clinical success rate was $77.2 \%$, and relief of obstruction was maintained from stent implantation until death in $108 / 122$ of the patients $(88.5 \%)(6)$. Taken together, the results of these studies and of the current study provide evidence that the long-term clinical efficacy of SEMS can be maintained until death in the great majority of patients. Furthermore, the benefits of stenting can be of high value in obstructed patients with a relatively short expected survival, as surgery in these patients may even be considered unethical, having a profoundly negative impact on quality of life $(2,13)$.

In this study, technical success was achieved in $95.5 \%$ of the patients, a rate consistent with the largest published pooled analysis, which reported a technical success rate of $93.24 \%$ (range 64 to $100 \%$ ) (11). In the current study, there were no differences in the technical success rates for stents placed in the right versus the left side of the colon (93.8 vs. 95.9\%), suggesting that the through-the-scope technique makes all tumour locations accessible from a technical perspective. In the present study, immediate clinical success was observed in $91.0 \%$ of the patients who were able to avoid surgery. These results were in keeping with the results of the previously cited pooled analysis, in which clinical success was achieved in $88.56 \%$ of the patients (range, 55-100\%) (11).

When SEMS placement is considered for definitive palliation of malignant colorectal obstruction, safety is an important issue. The most frequent complications are perforations, stent obstruction, stent migration and bleeding. In this study, the complication rate was $22.5 \%$, very similar to the results of other studies with an overall complication rate of $25 \%$ $(6,11,14)$; however, relevant complications (namely perforations) are not common. In this study, perforation was seen in $4.5 \%$ of patients. This result is in line with the literature, in which perforation occurred in 0 to $9 \%$ of cases, with an average of $5 \%(6,7,11,13,14,21)$. Proposed risk factors for perforation include balloon predilatation, concomitant chemotherapy and bevacizumab-based chemotherapy $(5,6,13,17,18,23)$. In this study, balloon dilatation was not done and chemotherapy was not associated with perforation in multivariate analysis, as previously reported by others (1). However, the addition of bevacizumab to cancer therapy significantly increases the risk of colorectal perforation, and this risk is further increased in patients submitted to SEMS placement for palliative colorectal obstruction $(5,13,23)$. In this study, the stent migration rate was $5.1 \%$, which is low when compared with older studies reporting values between 9 and $16 \%(11,14)$. In fact, the problem of stent migration seems to be declining as a result of increasing use of stents specifically designed for colons with larger diameters. In the current study, $56.2 \%$ of the patients were submitted to stents with diameters of $25 \mathrm{~mm}$, and this approach may explain our low migration rate. In this study, the multivariate logistic model showed a non-significant trend by which the use of palliative chemotherapy constituted a risk factor for migration. This result suggests that concomitant chemotherapy may enhance tumour reduction, leading to migration in the long-term. One of the most common complications of colorectal stenting is stent reobstruction. In this study, the stent occlusion rate was 
$9.0 \%$, which is in line with recent literature reporting an occlusion rate between 9 and $17 \%(1,4,6,12)$. Recently, the insertion of an additional stent has become standard in the treatment of stent occlusion. In our study, among the $9.0 \%$ of patients in whom reobstruction was seen, subsequent stent placement further increase the benefit of stenting in the majority $(7 / 8,87.5 \%)$ of patients treated with SEMS.

Several limitations of our study should be taken into account. First, this was a study with a retrospective design limiting the number of included patients because some of the identified consecutive patients had incomplete data and were excluded from the analysis. Our data may therefore have been subject to selection bias. Another potential weakness is the single-arm design, with no comparison to other available treatments, especially to palliative surgery. We suggest that further prospective randomised studies are needed. Surgery must be compared to endoscopic stenting in a large population in order to have adequate power to detect minor differences in outcome. In these proposed studies, long-term complications and quality of life should be carefully evaluated. The endoscopists involved in the procedures were very experienced, and we cannot exclude a poorer outcome in community or district general hospitals. However, in a large cohort of patients Garcia-Cano et al. reported similar results between referral centres and smaller hospital suggesting that colonic stent placement could be feasibly performed in general endoscopic practice (20). The strengths of our study are the design, which allowed us to follow a cohort of patients from stent insertion until death in all cases, and the relatively large sample size.

In conclusion, our data suggest that the placement of a SEMS for definitive palliation of incurable malignant colorectal obstruction is a useful tool that can provide sustained relief of obstruction without reintervention in approximately $75 \%$ of patients. The procedure provides rapid and effective relief of obstruction and is associated with acceptable morbidity, acceptable need for reintervention and minimal mortality.

\section{REFERENCES}

1. Lee HJ, Hong SP, Cheon JH, Kim TI, Min BS, Kim NK, et al. Longterm outcome of palliative therapy for malignant colorectal obstruction in patients with unresectable metastatic colorectal cancers: endoscopic stenting versus surgery. Gastrointest Endosc 2011;73:535-42.

2. Repici A, Ferreira DP. Expandable metal stents for malignant colorectal strictures. Gastrointest Endoscopy Clin N Am 2011;21:511-33.

3. Self-expanding metal stents as non-surgical palliative therapy for malignant colonic obstruction: time to change the standard of care? [editorial]. Gastrointest Endosc 2007;66:928-30.

4. Fernández-Esparrach G, Bordas JM, Giráldez MD, Ginès A, Pelissé M, Sendino O, et al. Severe complications limit long-term clinical success of self-expanding metal stents in patients with obstructive colorectal cancer. Am J Gastroenterol 2010;105:1087-93.
5. van Hooft JE, Fockens P, Marinelli AW, Timmer R, van Berkel AM, Bossuyt PM, et al. Early closure of a multicenter randomized clinical trial of endoscopic stenting versus surgery for stage IV left-sided colorectal cancer. Endoscopy 2008;40:184-91.

6. Small AJ, Coelho-Prabhu N, Baron TH. Endoscopic placement of selfexpandable metal stents for malignant colonic obstruction: long-term outcomes and complication factors. Gastrointest Endosc 2010;71:56072.

7. Repici A, Fregonese D, Costamagna G, Dumas R. Kähler G, Meisner $\mathrm{S}$, et al. Ultraflex precision colonic stent placement for palliation of malignant colonic obstruction: a prospective multicenter study. Gastrointest Endosc 2007;66:920-7.

8. Self-expanding metal stents in malignant colonic obstruction: have we covered all angles? [editorial]. Gastrointest Endosc 2007:67:937-9.

9. Watt AM, Faragher IG, Griffin TT, Rieger NA, Maddern GJ. Selfexpanding metallic stents for relieving malignant colorectal obstruction: a systematic review. Ann Surg 2007;246:24-30.

10. Dohmoto M, Rupp KD, Hohlbach G. Endoskopisch implantierte Prothese beim Rektumkarzinom. Dtsch Med Wochenschr 1990;115:915.

11. Sebastian S, Johnston S, Geoghegan T, Torreggiani W, Buckley M. Pooled analysis of the efficacy and safety of self-expanding metal stenting in malignant colorectal obstruction. Am J Gastroenterol 2004;99:2051-7.

12. Jung MK, Park SY, Jeon SW, Cho CM, Tak WY, Kweon YO, et al. Factors associated with the long-term outcome of a self-expandable colon stent used for palliation of malignant colorectal obstruction. Surg Endosc 2010;24:525-30.

13. Manes G, de Bellis M, Fuccio L, Repici A, Masci E, Ardizzone S, et al. Endoscopic palliation in patients with incurable malignant colorectal obstruction by means of self-expanding metal stent: analysis of results and predictors of outcomes in a large multicenter series. Arch Surg 2011;146:1157-62.

14. Ptok H, Meyer F, Marusch F, Steinert R, Gastinger I, Lippert H, et al. Palliative stent implantation in the treatment of malignant colorectal obstruction. Surg Endosc 2006;20:909-14.

15. Baron TH. Colonic stenting, technology, and outcomes for malignant and benign disease. Gastrointest Endoscopy Clin N Am 2005;15:757-71.

16. Law WL, Choi HK, Chu KW. Comparison of stenting with emergency surgery as palliative treatment for obstructing primary left-sided colorectal cancer. Br J Surg 2003;90:1429-33.

17. Xinopoulos D, Dimitroulopoulos D, Theodosopoulos T, Tsamakidis K, Bitsakou G, Plataniotis G, et al. Stenting or stoma creation for patients with inoperable malignant colonic obstructions? Results of a study and cost-effectiveness analysis. Surg Endosc 2004;18:421-6.

18. Fiori E, Lamazza A, De Cesare A, Bononi M, Volpino P, Schillaci A, et al. Palliative management of malignant rectosigmoidal obstruction. Colostomy vs. endoscopic stenting. A randomized prospective trial. Anticancer Res 2004;24:265-68.

19. Repici A, De Caro G, Luigiano C, Fabbri C, Pagano N, Preatoni P, et al. WallFlex colonic stent placement for management of malignant colonic obstruction: a prospective study at two centres. Gastrointest Endosc 2008;67:77-84.

20. García-Cano J, González-Huix F, Juzgado D, Igea F, Pérez-Miranda M, López-Rosés L, et al. Use of self-expanding metal stents to treat malignant colorectal obstruction in general endoscopic practice (with videos). Gastrointest Endosc 2006;64:914-20.

21. Small AJ, Baron TH. Comparison of Wallstent and Ultraflex stents for palliation of malignant left-sided colon obstruction: a retrospective, case-matched analysis. Gastrointest Endosc 2008;67:478-88.

22. Repici A, Adler DG, Gibbs CM, Malesci A, Preatoni P, Baron TH. Stenting of the proximal colon in patients with malignant large bowel obstruction: techniques and outcomes. Gastrointest Endosc 2007;66:940-4.

23. Hapani S, Chu D, Wu S. Risk of perforation in patients with cancer treated with bevacizumab: a meta-analysis. Lancet Oncol 2009;10:55968. 